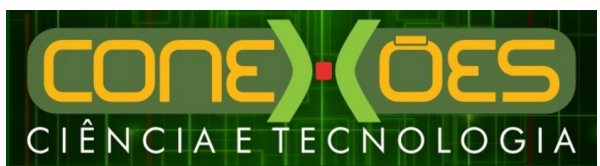

\title{
O TURISMO E A METRÓPOLE: ALGUMAS CONSIDERAÇÕES TEÓRICAS
}

\author{
Enos Feitosa de Araújo \\ Instituto Federal de Educação, Ciência e Tecnologia do Ceará - IFCE \\ campus de Fortaleza \\ $<$ enosfeitosa@gmail.com>
}

DOI: $10.21439 /$ conexoes.v11i5.1281

\begin{abstract}
Resumo. Nos últimos anos, a metrópole é um dos espaços mais relevantes na lógica capitalista mundial. É nela que concentram os melhores e mais diversificados serviços, bem como a infraestrutura física e virtual. É nas metrópoles que também se concentram os maiores fluxos turísticos (tanto emissores como receptores) e assim, as dinâmicas turísticas se relacionam cada vez mais com as dinâmicas metropolitanas. Partindo da Europa para o mundo, o turismo [relacionado com as metrópoles] torna-se uma prática difundida e comum na produção socioespacial de nossa sociedade.
\end{abstract}

Palavras-chaves: Metrópole. Turismo. Conceitos.

\begin{abstract}
In recent years, the metropolis is one of the most important areas in the world capitalist logic. It is there that concentrate the best and most diversified services, as well as physical and virtual infrastructure. It is in cities that also concentrated the largest tourist flows (both issuers and receivers) and thus the tourist dynamics relate increasingly to the metropolitan dynamics. From Europe to the world, tourism [related to the metropolises] becomes a widespread and common practice in the socio-production of our society.
\end{abstract}

Keywords: Metropolis. Tourism. Concepts.

\section{INTRODUÇÃO}

Falar sobre turismo é uma tarefa árdua, seja pela multiplicidade de vertentes nas mais variadas ciências, seja pela "quantificação ou qualificação" dos fluxos decorrentes. Ou seja, pela forma de vê-lo como um fenômend ${ }^{1}$ ou como já discorremos até aqui, como uma ati-

\footnotetext{
${ }^{1}$ Fenômeno é um termo que vem do latim "phaenomenon" e do grego "phainomenon" que significa: "o que é visto, o que surge aos olhos", ou "aparecer à luz". Tal vocábulo é conceituado como princípio filosófico frente à Fenomenologia, principalmente dirigida pelo matemático e filósofo Edmund Husserll. Tal sentido do "fenômeno" é considerado como "não somente o que aparece ou se manifesta ao homem em condições particulares, mas aquilo que aparece ou manifesta em si mesmo, como é em si, sua essência" ABBAGNANO 1999 p.437). Ao abrangermos a fenomenologia no turismo, podemos destacar que está vertente enxerga o "turismo como um fenômeno" abarcando várias ciências sociais, onde se destaca a Filosofia, Antropologia, História, entre outras, que procura construir teorias mais sólidas sobre o turismo. Temos como destaque nesta vertente os autores Netto, Noguero e Jäger (2011), Molina (2009), que veem o turismo como "fenômeno". A Geografia - notadamente a intitulada "do Turismo" - também inclui tais questionamentos, mas pela sua base majoritariamente quantitativa, procura ainda associar a ideia da "materialidade" quanto ao entendimento dos impactos de tal atividade
}

vidade econômica com ações direcionadas à recreação e ao lazer. Ele se apresenta num cenário global-local, com dimensões diversas, e principalmente, com várias regiões e espaços distintos que de certa forma, são homogeneizados pelo discurso e consolidação turística. Partirmos da premissa que o turismo se vinculou, nas últimas três décadas, particularmente aos fluxos metropolitanos, seja pela emissão e/ou captação de turistas, seja pelos agentes turísticos envolvidos.

\section{A METRÓPOLE E TURISMO: alguns apon- tamentos teóricos}

Esta dimensão metropolitana iniciou-se, pioneiramente, na Inglaterra ainda no século XIX com o desenvolvimento industrial e petroquímico, chegando, posteriormente, ao âmbito financeiro. A metropolização influenciou muitos países, como a produção espacial do espaço norte-americano, que também por ser um dos líderes da segunda revolução industrial, presenciou suas cidades (PEARCE; KRIEGER 2000 ). 
O TURISMO E A METRÓPOLE: ALGUMAS CONSIDERAÇÕES TEÓRICAS

tornarem-se "metrópoles" onde se destaca New York, designada de Big Apple. Posteriormente, outras localidades como São Paulo, Buenos Aires, Pequim, entre outras, também seguiram a mesma direção (HARVEY 2004).

A metrópole $2^{2}$ como produto espacial que se põe ao avanço dos sistemas técnicos e tecnológicos do sistema capitalista que se ampliou principalmente em meados do século XX, influenciava a nova forma de (re) produção espacial inspirada pela urbanização, industrialização, e principalmente,

Observa-se que as mudanças nos elementos que são colocados como fundamentais ao poder metropolitano, seguem percursos do desenvolvimento do próprio sistema capitalista. Se no final do século XIX e princípio do XX, o destaque era o comércio regional e o sistema bancário/financeiro, isso remete a dois aspectos importantes: tanto nos EUA como na Inglaterra, estava em curso o avanço do capitalismo financeiro, do qual a produção é elemento crucial. E as estruturas destes sistemas localizavam-se na metrópole, bem como aquela do comércio regional a partir do qual realizava - se amplo processo de distribuição de mercadorias. (...). Em outros termos, no período referido acima, a metrópole funcionalmente considerada, era lócus do poder via comércio regional, produção industrial, sistema bancário e comunicação, além dos elementos políticos e culturais. A partir dos anos

\footnotetext{
${ }^{2} \mathrm{O}$ conceito de "metrópole" nasce com o de "cidade-mãe", do século XIX, pelos significados que tentam explicar as várias mudanças ocorridas por conta das novas técnicas e tecnologias. Inúmeros cientistas da época questionam a relação urbano-metropolitana: se é complementar ou se é concorrente. Assim, trocam-se os laços de significados metropolitanos de quantitativos para qualitativos (FRESCA 2011). No que tange aos conceitos pioneiros de "metrópole" Santos (2009) salienta que essas mudanças abruptas na sociedade (leiase contexto de metropolização) tornaram as definições de "cidade", "metrópole", entre outras, conceitos geográficos insuficientes para as novas dinâmicas. Assim, propõe que os geógrafos consigam avançar para reconceituar, reconstruir novos conceitos, principalmente os de metrópole. Outros aspectos relevantes são as estruturas urbanas, as intraurbanas, em que se analisa o comportamento da metrópole na produção de seu próprio tecido, ou seja, a análise intra metropolitana. Na condição de nó de várias articulações socioespaciais, a metrópole reflete, concomitantemente, "dispersão, agregação e segregação", sendo contraditória por natureza (LEFEVBRE 1999) Araújo (2012 p.52) ao abordar o espaço metropolitano de Fortaleza destaca também que "Assim, a metrópole é híbrida porque o espaço é híbrido". Por mais que as dinâmicas metropolitanas sejam relevantes na atualidade, a sua (i) materialidade é relacionada com o espaço, com simultaneidades dinâmicas, constantemente modificadas pelas novas relações geradas pelas multiplicidades de agentes e ações (DOREEN 2009).
}

de 1950, em linhas gerais, ocorreram alterações nos elementos do poder metropolitano (...) dominando a economia com sedes nas metrópoles por causa das economias externas, facilidades de contatos inter organizacionais, disponibilidade de serviços comerciais, consultorias diversas, informação e acessibilidade (FRESCA, 2011, p.41).

Em outros termos, a metrópole concentrava o poder em suas mais variadas escalas econômicas, espaciais e sociais. Santos (2006, p.101) ao destacar que “(...) o tempo que está em todos os lugares é o tempo da metrópole" refere-se à hierarquia e a intitulada onipresença da metrópole quanto à disposição dos lugares e sua relevância nos contextos econômicos e sociais. Em outros termos, a metropolização tornou-se uma importante dimensão espacial do último quartel do século XX.

No que se indica dos fluxos turísticos metropolitanos, ampliam-se, prioritariamente nos anos 1950 (pósguerra), as cidades e metrópoles com maior desenvoltura econômica que detinham uma maior concentração - e hoje ainda existe tal centralização - da maioria dos turistas. Dados da Organização Mundial do Turismo OMT (2011) revelam que o número de turistas em 1950, era de menos de 2 milhões, acumulando 25 milhões em toda década, e chegando à mais de um bilhão de pessoas em 2013.

O que vemos é a massificação do turismo que inseriu novos destinos, notadamente nos países menos desenvolvidos, como os países da América do Sul, Central e Ásia. Temos aqui uma nova lógica de fluxos e fixos do turismo perante países emissores, como aos países receptores - atrelados à relevância das metrópoles e regiões (DANTAS; FERREIRA; CLEMENTINO, 2012).

Para Rejowski et al. (2002) "o número de empreendimentos voltados ao turismo aumentaram exponencialmente em todos os países, mas iniciam-se nos anos 1960-70, um período em que os países menos desenvolvidos recebem investimentos - tantos do Poder Público como da iniciativa privada - em vários projetos de grande escala"; um dos que podemos destacar é a localidade de Cancun, construída no final dos anos 1960 e início dos anos 1970, especialmente para o turismo, conforme aponta Boullon (2002), um dos autores do Planejamento Turístico.

O planejamento espacial do turismo tornou-se uma essencial forma de crescimento econômico ainda nos anos de 1960, principalmente na América Latina e em países subdesenvolvidos. Boullon (2002) justifica a localidade de Cancun "pela necessidade de atrair recursos financeiros para o México". Tal conduta de abertura mundial é comprovado pelos fluxos internacionais. 
É a partir dos anos 1950-1960 que a esfera governamental captura o turismo para o planejamento espacial. Como esta atividade é orientada para o mercado, há a necessidade de atração e articulação das organizações privadas. O Estado tem o interesse em promover o desenvolvimento nacional e regional sendo que com isso pode fomentar políticas públicas diretas e/ou indiretas de turismo ou provocar um ambiente propício para o desenvolvimento da atividade (TELES, 2009).

Tais fatores atrelam-se ao modo de vida urbano/metropolitano do século XX e apresentam o cenário ideal para seu desenvolvimento, em uma adaptação ao cotidiano das pessoas.

\section{A partir de 1950 houve uma nova era cultural, na qual o lazer teve um impacto na formação de uma moral coletiva orientada ao prazer. $\mathrm{Na}$ década seguinte, inventaram os "três $S$ " do tu- rismo. Segundo o jornal inglês Sunday Ti- mes, viajava-se em busca de sun (sol), sand (areia) e sex (sexo); o periódico ainda com- parou os "três S" ao panis et circenses (pão e circo) da Roma Antiga (BADARÓ, 2006 p.42).}

Pereira (2012) associa que "tal modo de vida urbano (ou mais diretamente, aquele vinculado ao metropolitano) reúne o turismo e a vilegiatura (outra forma de lazer) às demandas existentes pela sociedade". O lazer transforma-se em uma forma ideal para o descanso e conforto dos cidadãos urbanos no sentido que Lefevbre (2001) propõe: "que o modo de vida urbano seja levado pelas ações dos cidadãos a outros lugares, mesmo que não tenha em sua amplitude, a vida urbana”. Em outras palavras, o turismo associa-se à urbanização e o modo de vida urbano porque os cidadãos são urbanos; ou conforme Urry (2001) enfatiza o turista com seu olhar. Então ao constituírem novos lugares turísticos ou a (re) invenção de outros, a vinculação com agentes espaciais - notadamente metropolitanos - com fluxos cada vez mais nacionais e internacionais, o lugar turístico materializa-se num nó de uma rede de lugares de âmbito internacional.

Desta forma, o turismo possui em sua construção conjunta com seus agentes espaciais e turísticos, a promoção de re (invenções) e símbolos aleatórios, que faz de certa forma, uma nova representação espacial. Boyer e Ribeiro (1999) ao criticar o turismo face a seus significados observa que, "os espaços privilegiados do turismo são aqueles que são selecionados perante a própria conjuntura socioespacial que é formada em cada território”.

O turismo é um tipo de consumo diferente dos outros, pois se realiza em outro local e não visa à satisfação de uma necessidade fundamental do homem: ele não é um dado da Natureza ou do patrimônio histórico, pois nenhum lugar é turístico em si, nenhum sítio merece ser visitado, como diz a literatura turística; o turismo é um produto da evolução sociocultural (BOYER; RIBEIRO, 1999. p.16).

Conforme o autor, o turismo e sua visão é resultado da evolução sociocultural da civilização humana (notadamente a ocidental) que se promove sobre o espaço e principalmente sobre as pessoas. O espaço turístico é produzido a partir das intencionalidades realizadas, ou seja, as relações entre o sujeito [homem em suas ações] e o espaço, ao mesmo tempo, em que se cria uma imagem em torno deste espaço. De modo geral, o espaço turístico é antes de tudo, formado por representações ARAÚJO; PEREIRA; PAULA, 2010.

Jr e Barretto (2001) associa a "formação de identidades forjadas pela influência de turistas nestes lugares, que são fictícias ou em movimento". Os fluxos, cada vez mais intensos, transmitidos na forma do turismo de massa - promovem mudanças profundas e significativas em curto período temporal, podendo em tal caso, provocar impactos sociais, produtivos e principalmente ambientais.

Podemos dizer, que o turismo do século XX associase aos novos comportamentos, costumes, éticas e fundamentalmente, as novas visões sobre o espaço. A turistificação dos lugares é nada mais nada menos que a implantação de infraestrutura para o turismo e ao mesmo tempo, a promoção de novos fluxos e fixos urbanos e metropolitanos.

Por outro lado, Dreyfus-Signoles (2002) analisa o "espaço turístic 3" ou uma "dimensão" do espaço voltada ao turismo. Knafou (1996) também entende que são raros os "espaços meramente turísticos", ou seja, aqueles que apenas vivem desta atividade, sendo estas raridades então, considerados como enclaves turísticos que são espaços que possuem a produção espacial direta ao turismo, que a urbanização turística incentiva.

3 Urry (2001) quando fala sobre espaço turístico, fala sobre sua "construção": "Assim, os turistas (até que inconscientemente) e os promotores turísticos passam gradualmente a construir bastidores, de maneira forçada e artificial. Os "espaços turísticos" organizam-se, portanto, em torno daquilo que MacCannell denomina uma "autenticidade encenada". (...) MacCannell argumenta que os "pseudoacontecimentos" resultam das relações sociais do turismo, e não de uma procura individualista do inautêntico (URRY 2001 p.25). Desta forma, podemos considerar as "invenções turísticas" aqueles "espaços" que possuem construções imagéticas e representativas em torno dele, podemos citar vários casos internacionais, como a Disneylândia, vários parques aquáticos, entre outros. 
Com a emergente atividade turística - agora vinculado à urgente e crescente lógica metropolitana - as características que esta atividade ocasiona, diretamente e/ou indiretamente, acompanhará as principais tendências e seu emaranhado de relações que as metrópoles e seus poderes de decisão possuirão. Em suma, o turismo associa-se diretamente à produção espacial, que na característica atual, é ao mesmo tempo regional e metropolitana, em meados do século XX.

Tal posição do turismo no contexto internacional mostra-se pela facilidade de seu desenvolvimento, seja pela iniciativa privada, seja pela inserção em políticas públicas regionais e nacionais. Seu impacto na economia é crescente, agregando outras atividades em seu entorno, como a alimentação, artesanato, transportes, entre outros. O PIB internacional desta atividade passou de US\$ 50 milhões em 1950 para US\$ 1,1 trilhão em 2013 (OMT, 2014). Então, o turismo apresenta-se como esta atividade econômica e prática de lazer, em uma ambiguidade socioespacial, conforme o geógrafo Hoerner (2011, p.77) observa

A invenção do turismo de massa está, portanto, muito ligado à necessidade de uma atividade econômica nova e vigorosa, depois da confluência progressiva de um certo número de condições (aumento do tempo livre, elevação dos salários, melhoria dos transportes). (...) O turismo torna-se, assim, a principal atividade dos lazeres. O turista tem duas origens: a do aristocrata que tem os meios e o gosto pelas viagens, e a do explorador, que tem paixão pela descoberta. Ora, o turismo de massa moderno está em conflito em ambos $(\ldots)$

Desta forma, as ambiguidades sobre os impactos resultantes do turismo são diversas, seja pela forma social, econômica ou espacial. Davidovich (2003) destaca que é "nas metrópoles que a diversidade de sujeitos e de interesses se concentra, motivado pela expansão de polarização espacial e pela abertura de vários tipos de sujeitos e classes sociais, como estrangeiros e até mão de obra de alta qualificação".

Pereira (2012) evidencia que a "metropolização não é um processo único e que se constitui de variações abrangendo diversas escalas geográficas. E que a hierarquia de lugares é motivada, principalmente, pelo poder das metrópoles e pela força de decisão à vista das escalas regionais e continentais". Deste modo, os turistas modernos originam-se prioritariamente das metrópoles e das grandes aglomerações urbanas.

Estas características apontam para a adaptação do turismo às condições econômicas e espaciais do sistema capitalista mundial. O geógrafo Hoerner no seu clássico livro Geopolítica do Turismo aponta como o turismo reflete as condições de (in) estabilidade da economia e conflitos geopolíticos, que segundo o próprio autor, o considera como um tipo de indústria ${ }^{4}$ que estaria ligado à pós-modernidade.

Mas este autor faz uma análise interessante sobre os impactos do turismo nas novas geopolíticas e políticas internas e externas dos países e lugares. Existem novas formas de ver o mundo e de relacionar-se no mundo em que, forjados pelo discurso de globalização, o turismo torna-se uma maneira de relacionar-se no mundo em sua amplitude social e humana.

Tal cenário faz com que o turismo se adapte a essa lógica de rede de lugares capitaneado, principalmente, pelas grandes metrópoles, já que

Uma nova dinâmica urbana tem se desenvolvido com o processo de reorganização do capitalismo em escala mundial, envolvendo diversos pontos do planeta, através a extensão de redes e de fluxos. (...) Mudanças têm, portanto, lugar na espacialidade, que compreende diversas formas de concentração urbana: desde a grande cidade a centros em conurbação, desde a metrópole à formação de extensas manchas urbanas, que adquirem conotação regional, como cidades-região, que contêm a metrópole e outras cidades. São áreas consideradas, em tese, especialmente favoráveis a abertura para o mercado mundial devido a capacitação em recursos humanos e econômicos, a disponibilidade de infraestrutura eficiente e de equipamento técnico. A chamada cidade-região global corresponderia, assim, a uma espacialidade específica de ajuste à lógica dominante do mercado Davidovich (2003, p.136).

4 Hoerner (2011) adota o turismo como "indústria" partindo do conceito de "habilidade de fazer qualquer coisa" ou "invenção, perícia". Aponta que o turismo tem fases semelhantes às transformações da industrialização". Há outras concepções, já discutidos aqui, como a "urbanização turística" que coloca o turismo como vetor de urbanização em comparação pactual como a industrialização, que comumente é considerado como ação para a realização da urbanização. Tal afirmação nos é insuficiente para considerar o "turismo" como um tipo de indústria. Podemos citar Netto 2005 que afirma que a indústria possui em seu caráter a transformação de bens, e que o turismo não teria na verdade, essa característica, mas sim "a construção de novas dinâmicas socioespaciais" ou a acumulação de dimensões no mesmo espaço. Parafraseando Haesbaert (2010) ao definir os conceitos espaciais, principalmente o de "região", o autor considera que a "arte" é a forma de inventar certas coisas materiais, que poderia ter o mesmo sentido de indústria, citado por Hoerner (2011). 
Então, o turismo ao mesmo tempo em que mantém a expansão internacional, concentra nas grandes metrópoles - e/ou cidades articuladas e hierarquizadas na lógica espacial regional e internacional - seus fixos e fluxos de origens diversas, sejam globais ou locais. Santos (2005) aponta que "o turismo, como qualquer outra atividade econômica, adapta-se ou simplesmente acompanha a consolidação do meio técnico científico informacional com todas as infraestruturas e ações espaciais que solidifica os fluxos e fixos".

\section{TURISMO INTERNACIONAL: fluxo de massa}

Portanto, com os aspectos metropolitanos que o turismo moderno e típico do século XX apresenta, a atividade ganha relevância mundial conjuntamente com o planejamento governamental. Cunha (1997) ao abordar as principais estratégias em nível mundial do turismo, coloca o desenvolvimento planificado (vinculado à ação estatal e geralmente concentrado em áreas metropolitanas), políticas públicas de turismo, produtos diferenciados, o desenvolvimento sustentável e a integração da população local como as mais importantes para manter o desenvolvimento do turismo.

Desta forma, ao apontarmos a vinculação do turismo ao planejamento metropolitano - notadamente nos países subdesenvolvidos, a partir dos anos 1950-60 e a forma de (re) urbanização, e até a "gentrificação" nas cidades e metrópoles mais avançadas, concordamos com Harvey (2005): o turismo é como uma alternativa confirmada para os fluxos de lazer ligados às grandes áreas do espaço mundial, onde as metrópoles se apresentam como áreas que conseguem fortalecer fluxos e fixos mundiais para a sustentação das atividades econômicas, de forma globalizante e crescente".

Quanto aos fluxos e fixos, temos uma tendência crescente de empreendimentos turísticos tanto nos países desenvolvidos e em desenvolvimento conforme $\mathrm{Pe}-$ arce e Krieger (2000). Seja pela ampliação das políticas públicas relacionadas ao turismo (que em muitos casos, chegava a financiamento dos empreendimentos) e pela abertura à iniciativa privada.

Badaró (2006) aponta que "em 1950 o número de turistas no mundo chegava a 25 milhões, dos quais, $73 \%$ estavam concentrados em apenas 5 países e $97 \%$ em 15 países, entre estes, especialmente os europeus". Tais fluxos indicam que o turismo parte das áreas metropolitanas. Os principais fluxos emissores são vinculados aos espaços metropolitanos, e em maioria, também são os fluxos receptores.

Em vista disto, o turismo dimensiona-se internacionalmente, mas as principais metrópoles - detentoras da hegemonia econômica - enredadas aos Estados-nações mais desenvolvidos mantém-se como os espaços "hierarquizadores" dos fluxos mundiais. Em suma, os deslocamentos ganham abrangência internacional, mas o poder de decisão continua nos espaços metropolitanos e econômicos de primeira ordem mundial.

Tais particularidades partem para um turismo predominantemente metropolitano em que as principais áreas de destaque econômicas relacionam-se inicialmente às áreas mais importantes de outros núcleos e países. Mas ao mesmo tempo em promove uma relação espacial internacional, ele motiva a interação do turista com o olhar do próprio local, por exemplo.

Percebemos, então, uma série de ambiguidades de significados e de características socioespaciais do turismo, que se consolida diante do discurso internacional. Essa internacionalização não homogeneíza os lugares, porém, ao mesmo tempo, fomenta certos padrões esperados nestes lugares, principalmente vinculados às propriedades urbanas e da sociedade capitalista (URRY, 2001).

Então, notamos aqui, com a internacionalização do turismo - sobretudo na Europa - os locais turísticos que são comparados entre si em suas similaridades e suas divergências socioespaciais. Inferimos, então, que o turismo possui em sua origem, à vinculação da regionalização e metropolização. Para Lencioni (2004), os dois processos (regionalização e metropolização) são concomitantes e paralelos produzindo dinâmicas socioespaciais mais intensificadas.

Diante desta internacionalização e dos lugares que promove modificações profundas na produção socioespacial (implantação de infraestrutura, como mudança de modo de vida e comportamentos) o turismo promove contradições ainda mais significativas na visão sobre o espaço. Do mesmo modo que ele padroniza as lógicas espaciais, diferencia-os, perante um tipo de fixidez espacial necessária para a solidificação de seus fluxos. Percebemos aqui uma incerteza, mas também a complementaridade de regionalização e metropolização no espaço.

Devem-se notar dois traços geográficos ou espaciais dos serviços relacionados com o turismo. Em primeiro lugar, tais serviços devem ser fornecidos aos objetos do olhar do turista ou, pelo menos, devem estar próximos a eles. Não podem ser providenciados em qualquer lugar. Os serviços proporcionados aos turistas desenvolvem-se em lugares muito particulares e não se pode transferi-los para outro lugar. Possuem uma determinada "fixidez espacial". Em segundo lugar, boa parte 
O TURISMO E A METRÓPOLE: ALGUMAS CONSIDERAÇÕES TEÓRICAS

da produção dos serviços envolve uma proximidade espacial entre os produtores e os consumidores do serviço em questão. Isso resulta da natureza de muitos produtos proporcionados aos turistas, tais como refeições, bebidas, uma ida ao parque de diversões, etc. Esses serviços envolvem uma conexão necessariamente próxima entre produtores e consumidores (URRY, 2001, p.96).

Cruz (2006) estabelece que "o turismo tem duas características intrínsecas à atividade que se vincula ao espaço: a) ele é antes de tudo, uma prática social; b) O espaço é o "produto" do turismo, ou seja, o turismo produz e/ou influencia na produção espacial". Tais características fazem do turismo tanto uma atividade econômica como uma prática de lazer, já que mesmo diante da supremacia de agentes de mercado e do estado, o universo do turismo não se restringe às ações e atores hegemônicos.

Por conseguinte, o turismo produz lugares turísticos relacionados à teia de convivência dos agentes hegemônicos (Estado, iniciativa privada, entre outros) bem como pelas relações dos turistas, habitantes locais com o lugar per si. Ou seja, a complementaridade da produção espacial do lugar turístico é compreender ao mesmo tempo tanto a sua materialidade, como sua imaterialidade (como símbolos e representações) que são criadas pelas práticas sociais e psicológicas nos espaços referidos (FRATUCCI, 2000).

Concordando que o turismo produz novos significados diante do espaço, principalmente vinculados às representações metropolitanas e globalizantes, Hoerner (2011) analisa a globalização do turismo em sua teoria sobre a temática em que propõe seis ordens de distância espacial, em níveis internacionais a partir dos turistas franceses e os seus olhares sobre o espaço turístico. Apresentamos aqui, a tendência dos turistas frente à relevância do espaço perante a distância.

Figura 1: Ordem de Distância dos visitantes europeus - 2000

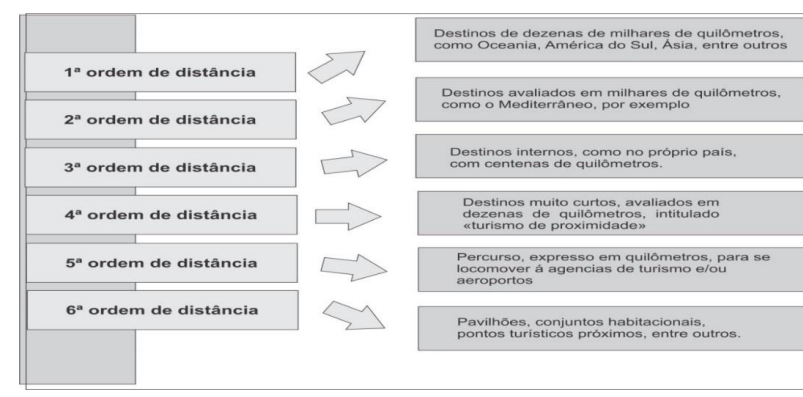

Fonte: adaptado pelo autor a partir de Hoerner (2011)
Para Hoerner (2011) "o turismo consegue ao mesmo tempo promover hierarquia de lugares quanto suscitar visões dos turistas sobre o turismo". Em suma, as distâncias (leia-se deslocamento no espaço geográfico) espaciais tornam-se cada vez mais longínquas em prol do conhecimento do turista sobre os lugares, tendo assim, as chamadas seis ordens espaciais:

$1^{\mathrm{a}}$ ) Relacionada a destinos turísticos mais longínquos, como outros continentes;

$2^{\mathrm{a}) ~ P a u t a d a}$ aos fluxos ainda no mesmo continente, mas em fronteiras e/ou países mais extremos;

$3^{\text {a) }}$ Elencada aos fluxos turísticos localizados no mesmo país, com limites de centenas de quilômetros;

$4^{\mathrm{a})}$ Que se intitula "turismo de proximidade" que pode ser na mesma região, mesmo município, ou mesma província;

$5^{\text {a) }}$ A que pode ser localizada em dezenas de quilômetros, normalmente em espaços relacionados à mesma cidade, como aeroportos, por exemplo;

$\left.6^{\mathrm{a}}\right)$ Refere-se a pontos relacionados ao turismo em pequenas distâncias, de poucos metros e quilômetros.

Estas ordens espaciais propostas por Hoerner (2011) nos remetem à hierarquização dos lugares [turísticos] diante do deslocamento do turista em toda a teia de relações que envolvem as atividades turísticas. Ou seja, o fazer turismo não é apenas visitar lugares, mas utilizarse da infraestrutura da cidade, desde que seja para compras e início do deslocamento de viagens para o percurso até a principal finalidade, que é o chegar ao local desejado.

Logo, podemos delinear o envolvimento do modo de vida urbano - e ainda mais diretamente, quanto aos fluxos emissores, a lógica metropolitana - na vida dos turistas. São os espaços urbanos, e notadamente os metropolitanos, os que mais se relacionam com os principais fluxos turísticos tanto nas escalas nacionais e internacionais.

Estabelece, portanto, a relação metropolitana do turismo emissor/receptor: se por um lado temos a (s) metrópole (s) como emissora (s) de fluxos turísticos, por outro, quanto à recepção de fluxos turísticos, além das metrópoles que também recebem fluxos, temos a presença de regiões turísticas que são (re) produzidas mediante a necessidade da demanda de fluxos turísticos existentes.

Apresentamos então, a hierarquia destes fixos e fluxos entre os países e lugares turístico. Se de um lado 
temos metrópoles que se relacionam quanto aos fluxos turísticos, por outro existem lugares turísticos que se apresentam como pontos em "redes regionais e/ou metropolitanas" e, mesmo estando relativamente distantes das áreas metropolitanas, apresentam destaques quanto aos fluxos turísticos nacionais e internacionais.

No Nordeste brasileiro, percebemos tal tendência e estabilização da metropolização e regionalização concomitante quanto à lógica turística, já que

[...] analisar o Nordeste brasileiro na contemporaneidade perpassa por consideração de processo de metropolização, intensificado em valorização de demanda de atividades de lazer e recreação, a reverter-redimensionar o quadro de ordenamento do espaço validado na monocultura e em política de industrialização. Compreender essa lógica significa considerar processo de globalização pelo qual passou e passa a citada região. Tomando como base o fenômeno de internacionalização de sua economia no tempo, considerarse-á duas dimensões fundantes, uma associada ao meio geográfico, enfocado como contínuo no tempo, e outra às variáveis social, econômica, política e tecnológica, cuja descontinuidade é a marca. A primeira se refere à base material concreta sobre a qual a outra se efetiva. A segunda permeia a lógica de tratamento do meio de formas diferenciadas, e que, por sua vez, justifica e dá sustentação ao conjunto de imagens representativas da região em diversos contextos históricos (DANTAS, 2013).

Confirma-se, portanto, o fortalecimento do turismo no Nordeste brasileiro quanto à metropolização ante a associação globalizante como destaca Dantas (2013). Como a industrialização foi a principal forma de urbanização e crescimento econômico na região nordestina brasileira nos anos 1950-60, temos atualmente, a metropolização e as demandas de lazer (sobretudo o turismo) como importantes vetores dessa nova lógica espacial. O que muitos autores, como Silva e Ferreira (2008, p.189) indicam para uma "metropolização turística' 5

$5 \sqrt[5]{\text { Silva e Ferreira }[2008)}$ registra que existe no Nordeste brasileiro uma relação entre o turismo e a metrópole, forma pela qual praticamente todos os Estados passam por interferência direta e indireta em mais variadas escalas e intensidades. Pois ao considerarmos que a "A metropolização, em seus diversos níveis, inclusive com a formação de megalópoles mundiais, é um fenômeno de grande expressão em nossos dias já que promove, sob a forma de redes, a complexa articulação inter setorial de questões econômicas, sociais, políticas e culturais em uma perspectiva inter escalar, do local ao global" percebemos que as
Em presença à emergente globalização, a constituição de novos fluxos turísticos internacionais que rompem a Europa e a América do Norte (particularmente os EUA e o Canadá) e que irão ampliar-se para os países menos desenvolvidos da América do Sul, até determinados países da África, Oceania e Ásia.

Para a OMT há uma previsão de 1,6 bilhão de turistas até 2020, sendo que destes, 1,2 bilhão serão interregionais e quase 400 milhões de pessoas estarão idealizando as viagens de longas distâncias. Os principais índices de crescimento de turistas serão no Leste da Ásia, Pacífico, Ásia, Oriente Médio e África com cerca de 5\% ao ano, enquanto a média mundial de crescimento deve girar em torno de $4,1 \%$ na América Latina, esse índice pode alcançar os $4,6 \%$.

Portanto, temos uma "metropolização" pelo/do turismo nas regiões mais distantes dos centros tradicionais (leia-se Europa) numa lógica de (des) concentração. Isto é, ao mesmo tempo em que temos a concentração e fluxos turísticos ainda na Europa e América do Norte, temos um crescimento considerável em praticamente todos os demais países.

Conforme afirma Santos (2006), temos uma "guerra de lugares que é agravada pela globalização perante a concorrência pela captação de recursos financeiros de origem regional, continental e internacional". O turismo é captado pela lógica econômico-financeira para a sobrevivência econômica articulada entre a região e a metrópole.

Do mesmo modo, a escala da metrópole e da região diante da interpretação e ótica espacial sobre o turismo torna-se necessária e relevante frente as novas formas econômicas da sociedade capitalista. E esta escala metropolitana amplia-se tanto para a ótica do mercado como para o planejamento estatal. O Estado, através de suas ações, vincula o turismo tanto ao planejamento regional como o metropolitano.

É desta forma que Braga (2006) mostra que "o planejamento turístico se relaciona com a lógica da vinculação do lugar turístico na presença de espaços que possuem em suas próprias características espaciais as polaridades suficientes para captação de recursos finan-

áreas metropolitanas possuem força inter estadual de forma principalmente vinculada aos espaços litorâneos, conforme Dantas (2013. p.197) também aponta. Então o autor, nesta abordagem metropolitana do turismo, conceitua que "Entende-se por metropolização turística o processo de expansão da região metropolitana preponderantemente centrada nas atividades de turismo, recreação e lazer, resultando em intensos mecanismos de interação entre a metrópole e a nova área. Temos aqui uma "metropolização turística" como um conceito para explicar as novas formas que o turismo produz no espaço nordestino a partir de relações nacionais e internacionais em hotéis, pousadas, resorts, segundas residências, entre outros empreendimentos similares e correlacionados. 
ceiros, tanto do Poder Público, como a iniciativa privada em suas mais variadas escalas".

Tais condutas incentivam os grandes fluxos turísticos diante de uma concorrência mundial, motivada pela articulação entre o Estado e a iniciativa privada, em que as principais regiões e metrópoles no mundo têm uma relevância para a estabilidade do turismo tanto nos contextos continentais, regionais, metropolitanos e mundiais.

Destarte, o turismo firma-se como uma prática econômica que se difundiu praticamente em todo mundo com grandes fluxos que cresce em ritmos médios de até $10 \%$ ao ano desde 1980. Se nos anos 1950, computou-se apenas 25 milhões de turistas, nos anos 1960 tal fluxo cresceu para 70 milhões; nos anos 1970 , os fluxos mundiais chegavam a cerca de 165 milhões, e nos anos 1980 alcança-se os consideráveis 278 milhões de pessoas, mesmo em épocas de recessão mundial.

Hoerner (2011) cita que "os anos 1980-90 considerados como a década da recessão na economia mundial especialmente atrelados às crises sucessivas de produção e escassez, além do discurso do desenvolvimento sustentável, o turismo apresenta variações positivas ante a instabilidade econômica mundial". A atividade prossegue com fluxos consideráveis até meados dos anos 1980 e 1990 passando de 278 milhões para 439 milhões, com acréscimo de 58\% em dez anos.

Apesar de Cunha (1997) relacionar o turismo à política e à economia mundial de forma intrínseca, o autor questiona sua sobrevivência diante da estagnação mundial que pelos fluxos das grandes metrópoles e regiões mundiais conseguem "neutralizar" a própria crise do sistema capitalista frente aos grandes lucros e fluxos de capital conforme Harvey (2006) aponta.

Podemos observar no gráfico da Figura 2, as etapas dos fluxos mundiais desde 1950 até os anos de 2007. Os principais índices de crescimento atrelam-se à lógica dos anos 1990-2000 com a abertura internacional de um grupo de economias menos desenvolvidas reforçadas com o discurso político-econômico-financeiro bipolarizado que reinava até o final dos anos 1990. São dados relevantes para a compreensão da espacialização dos fluxos turísticos. Apesar da predominância dos fluxos europeus, vê-se nitidamente a ampliação dos fluxos pela América (que deve ser relativizado pela presença de América do Norte com EUA e Canadá), Ásia e Pacífico.

Com o crescimento de turistas no contexto mundial, os Estados e continentes entram em uma concorrência de lugares com valores cada vez maiores. Em 2007 o número de turistas chegava a 880 milhões; nos anos posteriores, tais quantidades chegavam a 948 milhões
Figura 2: Milhões de turistas internacionais - por região de destino $-1950-2007$

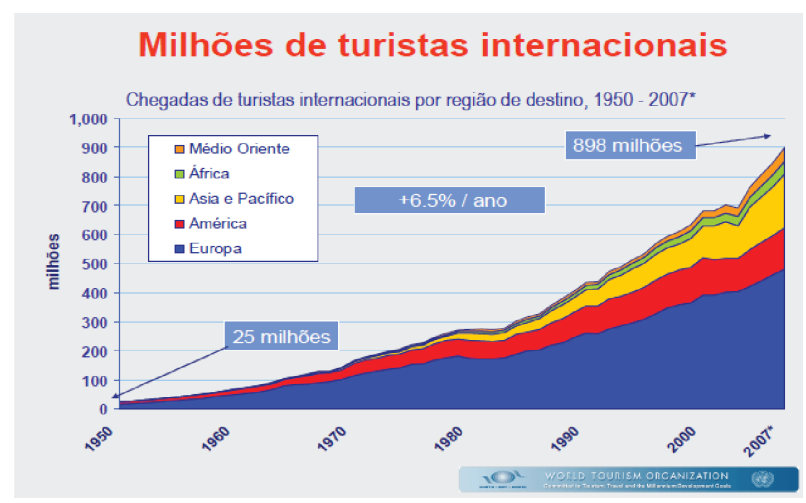

Fonte: OMT (2010)

em 2010, e no ano de 2013, quase 1,1 bilhão de turistas, com renda aproximada de US\$ 7,5 trilhões no ano de 2013.

Observa a OMT (2013), que tais fluxos nos últimos cinco anos, demonstraram que os países mais desenvolvidos detinham $65 \%$ da renda mundial, concentrada entre 10 a 15 principais países turísticos, enquanto os demais $35 \%$ ficavam em áreas menos desenvolvidos. Apesar de tal desigualdade, há uma leve tendência de crescimento dos países menos desenvolvidos, com os recursos e investimentos da iniciativa privada e de órgãos governamentais mundiais e nacionais.

Tais dados confirmam que esta lógica de fluxos turísticos (tanto no número de turistas como na sua economia) ocorre em países menos desenvolvidos, mas são as metrópoles regionais-locais que dominam tais fluxos-nacionais-internacionais como é no caso do Brasil exemplificado por São Paulo e Rio de Janeiro. No contexto internacional quem se sobressai são as metrópoles de Paris, Madri-Barcelona, Berlim, entre outras, conforme mostra o mapa da Figura 3 .

Conforme percebemos no mapa acima, pode-se aferir que mesmo havendo o crescimento de fluxos turísticos nos anos 2010, as metrópoles e regiões mais desenvolvidas dominam os maiores fluxos turísticos mundiais, principalmente localizados nos Estados Unidos, a Europa (Reino Unido, França, Espanha, Itália, Alemanha e Turquia, esta última como uma "surpresa") e a China juntamente com a Rússia como importantes áreas emergentes de fluxos consideráveis tanto para a Europa como para outros países da Ásia, como a Tailândia que apresenta fluxos maiores de 20 milhões de turistas por ano, por exemplo. 
O TURISMO E A METRÓPOLE: ALGUMAS CONSIDERAÇÕES TEÓRICAS

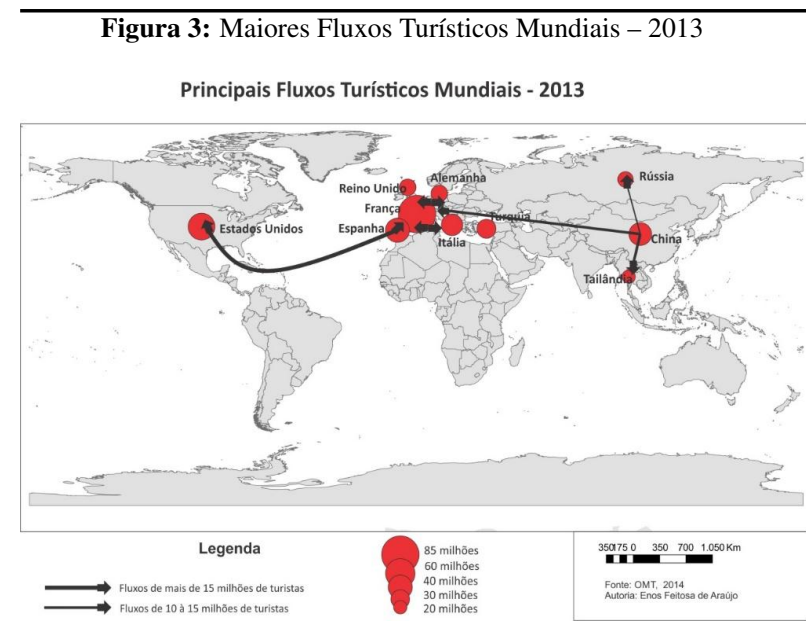

Fonte: OMT (2014)

\section{CONSIDERAÇÕES FINAIS}

O turismo apresenta fluxos cada vez maiores (tanto no número de turistas e quanto em renda) vinculados às grandes cidades/metrópoles e demais áreas de quase todo o planeta. Intrínseco à lógica de metropolização, vemos nas últimas décadas, auxiliado fundamentalmente pelo contexto da globalização, a consolidação de eventos (muitas vezes intitulado "megaeventos") esportivos e/ou de outras naturezas que transformam cidades e regiões em prol de um desenvolvimento econômico.

Tais características do turismo amarram o Estado, seu planejamento espacial e suas políticas públicas, ao discurso de vetor de desenvolvimento, principalmente em países menos desenvolvidos, como o Brasil e o México na América Latina. Vários são os planos e programas com finalidade de turistificar o espaço e promover sua urbanização, como os projetos de Cancun (anos 1960-70) e o de Barcelona (anos 1990).

Em vista disso, atrelado basicamente aos aspectos regionais e metropolitanos, o turismo ganha o papel de planejamento espacial, em que tais características híbridas (metropolitanas e regionais) serão firmadas em sua plenitude na produção espacial de vários países onde o Brasil se destaca. Enfatizaremos então, o seu papel na ótica das políticas públicas em suas mais diversas escalas espaciais.

\section{REFERÊNCIAS}

ABBAGNANO, N. História da Filosofia. : Ed. Presença, 1999.
ARAÚJO, E. F. d. As políticas públicas do turismo e os espaços litorâneos na região metropolitana de Fortaleza. Dissertação (mathesis) — Universidade Federal do Ceará, Departamento de Geografia Programa de Pós Graduação em Geografia, Fortaleza, CE, 2012.

ARAÚJO, E. F. de; PEREIRA, A. Q.; PAULA, E. Oliveira de. Turismo litorâneo na metrópole cearense: o caso de caucaia, ceará, brasil. Conexões-Ciência e Tecnologia, v. 4, p. 72-81, 2010.

BADARÓ, R. A. de L. Hotelaria à luz do direito do turismo. : Senac, 2006.

BOULLON, R. Planejamento do espaço turístico. Bauru: EDUSC, p. 111-187, 2002.

BOYER, M.; RIBEIRO, V. História do turismo de massa. : Edusc, 1999.

BRAGA, D. Planejamento turístico: teoria e prática. : Elsevier Brasil, 2006. v. 1.

CRUZ, R. d. C. A. da. Planejamento governamental do turismo: convergências e contradições na produção do espaço. In: Lemos, A.I.G [et al] (Orgs.). América Latina: cidade, campo e turismo. CLASCO, São Paulo,2006. 2006.

CUNHA, L. Economia e política do turismo. : McGraw-Hill: Alfragide, 1997.

DANTAS, E. W. C. Metropolização turística em região monocultora industrializada. Mercator, v. 12, n. 2, p. 65-84, 2013.

DANTAS, E. W. C.; FERREIRA, A.; CLEMENTINO, M. Construção da maritimidade nas sociedades tradicionais do brasil do passado. In: Francine Barthe-Deloizy; Angelo Serpa. (Org.). Visões do Brasil: estudos culturais em geografia. 1ed.Salvador: EDUFBA; Editions L'Harmattan,. v. 1, p. 87-112, 2012. 2012. p. 87.

DAVIDOVICH, F. Metrópole e contemporaneidade, algumas pontuações. In: Carlos, Ana Fani Alessandri e Lemos, Amália Inês Geraiges. (Orgs.). Dilemas Urbanos: Novas Abordagens sobre a Cidade. São Paulo: Contexto, 2003. : Editora Contexto, 2003.

DOREEN, M. Pelo Espaco: Uma Nova Politica da Espacialidade. : Bertand Brasil, Rio de Janeiro, 2009.

DREYFUS-SIGNOLES, C. L'espace touristique. : Editions Bréal, 2002. 
O TURISMO E A METRÓPOLE: ALGUMAS CONSIDERAÇÕES TEÓRICAS

FRATUCCI, A. C. Os lugares turísticos: territórios do fenômeno turístico. Geographia, v. 2, n. 4, p. 121-133, 2000.

FRESCA, T. M. Uma discussão sobee o conceito de metrópole (a discussion on the concept of metropolis). Revista da ANPEGE, v. 7, n. 8, p. 31-52, 2011.

HAESBAERT, R. Regional-global: dilemas da região e da regionalização na geografia contemporânea. Rio de Janeiro: Rio de Janeiro: Bertrand Brasil, 2010.

HARVEY, D. O Novo imperialismo. : Edições Loyola, 2004.

A Producao Capitalista Do Espaço. : Edições Loyola, 2005. 2006.

Os Espaços de esperança. : Edições Loyola,

HOERNER, J. M. Geopolítica do turismo. São Paulo: SENAC, 2011.

JR, Á. B.; BARRETTO, M. a. Turismo e identidade local: uma visão antropológica. Turismo e identidade local: uma visão antropológica, Papirus Campinas, 2001.

KNAFOU, R. Turismo e território: por uma abordagem científica do turismo. In: Adyr A. B. Rodrigues (org.). Turismo e Geografia. Reflexões teóricas e enfoques regionais. São Paulo: HUCITEC,1996,p.66-88. 1996. v. 2, p. 62-74.

LEFEVBRE, H. A revolução urbana. Belo Horizonte: Editora UFMG, 1999. $\overline{2001}$.

La producion de l'espace. Paris: Antrhopos,

LENCIONI, S. O processo de metropolização do espaço. uma nova maneira de falar da relação entre metropolização e regionalização. In: Sueli Schiffer. (Org.). Globalização e Estrutura Urbana. São Paulo: HUCITEC, FAPESP. 2004. p. 153-165.

MOLINA. Relatório Mundial do Turismo. 2009.

NETTO, A. P. Filosofia do turismo: teoria e epistemologia. : Aleph, 2005.

NETTO, A. P.; NOGUERO, F. T.; JÄGER, M. Por uma visão crítica nos estudos turísticos. Revista Turismo em Análise, v. 22, n. 3, p. 539-560, 2011.
Relatório Mundial do Turismo. 2011.

Relatório Mundial do Turismo. 2013.

Relatório Mundial do Turismo. 2014.

PEARCE, D. G.; KRIEGER, S. Geografia do turismo: fluxos e regiões no mercado de viagens. : Aleph, 2000.

PEREIRA, A. Q. A urbanização vai à praia: contribuições da vilegiatura marítima à Metropolização no nordeste do Brasil. Tese (phdthesis) — Programa de Pós-graduação em Geografia, Universidade Federal do Ceará, Fortaleza, CE, 2012

REJOWSKI, M. et al. Turismo no percurso do tempo. São Paulo: Aleph, 2002.

SANTOS, M. A urbanização brasileira. são paulo: Editora da universidade de são paulo, 2005. _. São Paulo: EDUSP, v. 3, 2005.

Por uma geografia nova da crítica da geografia a uma geografia crítica. São Paulo: Hucitec, 2006. 2009.

Natureza do espaço. São Paulo: EDUSP, v. 5,

SILVA, A.; FERREIRA, A. Três momentos da urbanização turística: estado, mercado e desenvolvimento regional no nordeste brasileiro, 1997-2007. In: Scripta Nova, Revista Electrónica de Geografia y Ciencias Sociales (Barcelona), v.12, p.270 (89), 2008. 2008. v. 12, n. 270, p. 89.

TELES, R. Fundamentos geográficos do turismo. : Elsevier, 2009.

URRY, J. Olhar do turista: lazer e viagens nas sociedades comteporânea. 3. ed. : São Paulo: SESC, 2001.

OMT. Relatório Mundial do Turismo. 2010. 